\title{
Adherence and resource use among patients treated with biologic drugs: findings from BEETLE study
}

This article was published in the following Dove Press journal:

ClinicoEconomics and Outcomes Research

18 September 2014

Number of times this article has been viewed

\section{Luca Degli Esposti' \\ Diego Sangiorgi' \\ Valentina Perrone ${ }^{2}$ \\ Sonia Radice ${ }^{2}$ \\ Emilio Clementi ${ }^{3,4}$ \\ Francesco Perone ${ }^{4,5}$ \\ Stefano Buda'}

'CliCon Srl Health, Economics and Outcomes Research, Ravenna, Italy; ${ }^{2}$ Unit of Clinical Pharmacology, Department of Biomedical and Clinical Sciences, L Sacco University Hospital, Università di Milano, Milan, Italy; ${ }^{3}$ Unit of Clinical Pharmacology, Department of Biomedical and Clinical Sciences, CNR Institute of Neuroscience, L Sacco University Hospital, Università di Milano, Milan, Italy; ${ }^{4}$ Scientific Institute, IRCCS E Medea, Lecco, Italy; ${ }^{5}$ Local Health Unit, Caserta, Italy
Correspondence: Luca Degli Esposti CliCon Srl, Health, Economics and Outcomes Research, Via Salara,

36 - 48I 00 Ravenna, Italy

Tel +3954438393

Fax +39544212699

Email luca.degliesposti@clicon.it
Objectives: Systemic administration of anti-tumor necrosis factor alpha (anti-TNF alpha) leads to an anti-inflammatory and joint protective effect in pathologies such as rheumatoid arthritis, psoriasis, and Crohn's disease. The aim of this study was to assess adherence to therapy, persistence in treatment (no switches or interruptions), and consumption of care resources (drugs, outpatient services, hospitalizations).

Methods: We conducted an observational retrospective cohort analysis using the administrative databases of five local health units. Patients filling at least one prescription for anti-TNF alpha between January 1, 2009 and December 31, 2011 were included and followed up for 1 year. Patients were defined as adherent if $>80 \%$ of the follow-up period was covered by drugs dispensation.

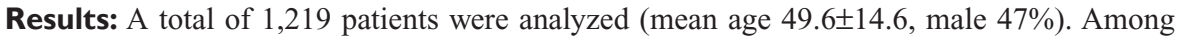
enrolled patients, $36 \%$ were affected by rheumatoid arthritis, and $31 \%$ and $10 \%$ were affected by psoriasis and Crohn's disease, respectively; other indications remained below these percentages. Thirty-four percent of patients (420) were treated with adalimumab, 51\% (615) with etanercept, and $15 \%$ (184) with infliximab. Among the $94 \%$ of patients who did not switch, those treated with infliximab had a higher rate of adherence across all indications ( $51 \%$ overall) when compared to that observed in patients treated with etanercept $(27 \%)$ or adalimumab $(23 \%)$. The mean annual nonpharmacological expenditure for each patient in analysis was $€ 988$ for adherent and $€ 1,255$ for nonadherent patients. Infliximab was associated with the lowest cost for all indications as determined by the multivariate generalized linear model.

Conclusions: Patients treated with infliximab were associated with higher adherence and persistence in treatment and lower costs, as compared to those treated with adalimumab or etanercept.

Keywords: anti-TNF alpha, therapy adherence, cost of illness

\section{Introduction}

Tumor necrosis factor alpha (TNF alpha) is a proinflammatory cytokine that plays a pivotal role in immune-mediated inflammatory diseases (IMID) such as rheumatoid arthritis (RA), inflammatory bowel disease, psoriatic arthritis (PsA), psoriasis, and ankylosing spondylitis (AS). These chronic and debilitating diseases lead to a significant decrease in quality of life secondary to severe functional impairment and pain. ${ }^{1-2}$

These disorders have a high prevalence (about $1 \%$ worldwide) $)^{3-6}$ and have a significant impact on patients and their families; in addition, IMID leads to a sizable burden to society due to high health care and non-health care-related costs. ${ }^{7}$ TNF-alpha antagonists (anti-TNF alpha) were among the first targeted immunotherapies introduced 
on the market, and they changed radically the management of patients with autoimmune and inflammatory diseases. ${ }^{8}$

Currently, there are two monoclonal anti-TNF alpha antibodies (adalimumab and infliximab) and a soluble TNF receptor fusion protein (etanercept) licensed for clinical use in Italy. ${ }^{9-11}$ These drugs bind to soluble and membrane forms of TNF alpha and neutralize the pathological effects of this cytokine in IMIDs. Adalimumab and etanercept are administered subcutaneously, while infliximab is administered as an intravenous infusion. Although all three drugs exert their beneficial effects through the blockade of TNF alpha binding to its receptor, there are differences in their site of action and molecular structure. These differences may explain the differential response to the three agents observed in individual patients, although there is no direct evidence to support this. ${ }^{12}$

Anti-TNF alpha agents have been found to be efficacious in clinical trial. ${ }^{13}$ The effectiveness of these drugs in the clinical practice depends, however, on the patients' compliance with medication taking. ${ }^{14}$

The parameters affecting medication taking are adherence, compliance, and persistence. In particular, nonadherence impacts on the chance of therapeutic success, delaying therapeutic remission and increasing disease severity. In patients with chronic pathologies such as RA, long-term treatment persistence is an important factor to evaluate the use of biological therapies in clinical practice. ${ }^{15}$

The impact on subsequent overall health care resource utilization of a therapy is determined primarily by the decrease in clinical effectiveness and by the relationship between loss of effectiveness and increased resource utilization. ${ }^{16,17}$ In general, poor treatment persistence has been associated with higher health care costs and utilization. ${ }^{18,19}$ As the main goal of health economic analyses is to inform and aid decisions for routine clinical practice, it is important to define the different factors in clinical trials versus (vs) real-life practice and measure their impact.

The objectives of this study were to assess the pharmacoutilization (adherence to therapy and staying on treatment) and the direct health care costs (drugs, hospitalizations, outpatient services) of adult patients treated with antiTNF alpha agents (adalimumab, etanercept, and infliximab) according to the therapeutic indication.

\section{Methods}

\section{Data source}

In this study we used the administrative databases of five Italian local health units (LHU) in Emilia-Romagna, Lazio,
Tuscany, Campania, and Lombardy. In Italy, each LHU has an information network that routinely records the volumes of expenditure of health care services in charge to the National Health System and thus dispensed free of charge to registered patients. This administrative database is complete and includes validated data, and it has been used in previous epidemiological studies. ${ }^{20}$ The Italian Ministry of Health defined these archives as $100 \%$ complete and $95 \%$ accurate. ${ }^{21}$

The data used in our study include territorial and hospitaldispensed drugs, demographic, hospitalization, and outpatient services data. We used the Territorial Pharmacy Database that routinely measures the volume of expenditure generated by the dispensing of drugs to enrollees. The data available in each prescription claim include the patient's national health number, the anatomical-therapeutic-chemical code of the drug dispensed, the number of packs dispensed, the number of units per pack, the dose, the unit cost per pack, and the prescription date. The Hospital Direct Drugs Distribution Registry contains the same data as the Territorial Pharmacy Database: the Beneficiaries' Database, listing patient demographic characteristics (date of birth, sex, start and end of registration dates within LHUs registry, the date of death, and the exemption codes); the Hospital Discharge Database, which includes all hospitalization data, with the main and secondary discharge diagnoses codes classified according to the International Classification of Diseases, Ninth Revision (ICD-9-CM) and the diagnosis-related group code; and the Outpatient Services Registry, including all laboratory investigations, instrumental tests, and specialist checkups requests and the dates on which these were performed.

No identifiers related to patients were provided to the researchers. The ethics committees for the LHUs approved the study.

\section{Cohort definition}

This study was an observational retrospective cohort analysis. Patients aged $\geq 18$ years who filled at least one prescription for anti-TNF alpha from January 1, 2009 to December 31, 2011 were included. The date of the first prescription of antiTNF alpha was defined as the index date, which represents the enrollment date of the individual patient, who was then followed for 1 year. The clinical characteristics of the patients enrolled in this study were also investigated in the 1-year period before the index date.

The patients were characterized according to hospital admissions, outpatient visits, and prescribed drugs during the follow-up and the characterization periods. We identified RA (ICD-9-CM code 714), Crohn's disease (ICD-9-CM code 555), 
PsA (ICD-9-CM code 696.0), psoriasis (ICD-9-CM code 696), AS (ICD-9-CM code 720.0) and ulcerative colitis (ICD-9-CM code 556) using ICD-9 codes retrieved from hospital admissions or exemption codes. The level of disease severity was measured using the MedStat Disease Staging Software $^{\circledR},{ }^{22}$ which classifies the pathologies on the basis of their complications (Stage 1: no complications; Stage 2: local complications; Stage 3: complications to multiple sites or systemic complications). This methodology has been widely used to compare disease severity in retrospective studies when detailed clinical outcome data are unavailable. ${ }^{23}$ The presence of previous use of disease-modifying antirheumatic drug and presence of concomitant use of methotrexate (MTX) were also evaluated.

\section{Adherence to therapy}

Adherence was calculated according to the method used by Catalan and LeLorier ${ }^{24}$ and determined by calculating the proportion of days covered for which a patient had a supplied medication in the time interval of 12 months after the enrollment date, using the drug prescription databases as follows:

\section{Proportion of days covered $=$ Total milligrams of the drug prescribed/defined daily dose}

Total coverage $(\%)=$ Sum of prescriptions coverage (days)/duration of the follow-up period (365 days) *100.

The use of defined daily doses was necessary because the dosage of infliximab depends on the weight of the patient and the administrative database does not provide this information. This method also allowed taking into account the induction period (if any). Patients were defined as adherent if $>80 \%$ of the follow-up period was covered by drug dispensation. Adherence was calculated separately for each anti-TNF alpha treatment and for each diagnosis. The measurement of "staying in treatment" was calculated for naïve patients and those without medication switches. The interruption of treatment was defined as the absence of prescriptions in the last 3 months of observation period. Finally, we analyzed only the patients without medication switches.

\section{Cost analysis}

Costs are reported in Euros $(€)$ currency. The costs for hospitalizations, treatments, and outpatient specialist services were classified as related and not related to the diseases in analysis.
Drug costs (pharmacological) were evaluated at the moment of the purchase; outpatient services costs were evaluated according to regional tariffs. Hospitalization costs were determined using the diagnosis-related group tariff. Mean annual total health care costs were estimated for each diagnosis and separately for different anti-TNF alpha treatments. A subanalysis was performed considering two cohorts that were defined as patients with an anti-TNF alpha adherence level treatment $>80 \%$ or $<80 \%$, respectively. Total health care and medical (nonpharmacological) costs were compared between these two cohorts.

\section{Statistical analysis}

We summarized data as mean and standard deviation for continuous variables and as the number (percentage) of study participants for categorical variables. A multivariable logistic regression model was performed to estimate the odds ratios (ORs) and 95\% confidence intervals (CIs) and to examine predictors of nonadherence to anti-TNF alpha therapy.

The model was used to identify differences in factors associated with persistence among treatment groups, adjusting for covariates such as age, sex, MedStat disease stage, and prior medication with biologics.

Model discrimination was assessed using the c-statistics, while model calibration was assessed using the Hosmer-Lemeshow test.

A generalized linear regression model with a gamma family and an identity link function were performed to examine the associations between total health care costs during the follow-up period and biologic agent, age, sex, MedStat disease stage, prior medication with biologics, and adherence level (>80\%).

To assess the linearity of the model, the Wald test was performed; to assess the goodness of fit of the model, influence statistics and residuals were analyzed. Patients with missing data and/or who moved away to another LHU during that interval were excluded.

$P$ values less than 0.05 were considered statistically significant. All analyses were performed using STATA 12.0 (StataCorp LP, College Station, TX, USA).

\section{Results}

A total of 1,219 patients satisfied the study criteria and were included in the analysis. The mean patient age in the study was 49.6 \pm 14.6 ; 579 patients (47\%) were male. Demographic and baseline clinical characteristics of the study population are shown in Table 1. Baseline patients affected by RA, 36\%; $31 \%$ had psoriasis, $10 \%$ had Crohn's disease (CD), 7\% had 
Table I Demographic and baseline clinical characteristics

\begin{tabular}{lll}
\hline & Number of subjects & $\%$ \\
\hline Beneficiaries & $\mathrm{I}, 150,000$ & \\
Patients with age $\geq 18:$ & 930,000 & $8 \mathrm{I}$ \\
Treated with anti-TNF- $\alpha$ & 1,219 & 0.13 \\
$\quad$ Adalimumab & 420 & 34 \\
$\quad$ Etanercept & 615 & $5 \mathrm{I}$ \\
$\quad$ Infliximab & 184 & 15 \\
Age of patients (mean \pm standard & $49.6 \pm 14.6$ & \\
deviation) & & \\
Male & 579 & 47 \\
Established (to biologic) & 364 & 30 \\
Diagnosis of patients & & 10 \\
$\quad$ Crohn's disease & & 3 \\
Ulcerative colitis & & 31 \\
Psoriasis & & 7 \\
Psoriatic arthritis & & 36 \\
Rheumatoid arthritis & & 3 \\
Ankylosing spondylitis & & \\
Not available & &
\end{tabular}

Abbreviation: anti-TNF- $\alpha$, anti-tumor necrosis factor-alpha.

PsA, 3\% had ulcerative colitis, and 3\% had AS. The diagnosis was not available for $11 \%$ of patients. Thirty percent $(n=364)$ of patients were already in treatment with biological drugs before the observational study period (established patients). During the study period, 420 patients (34\%) were treated with adalimumab, $615(51 \%)$ with etanercept, and 184 (15\%) with infliximab (Table 1). The level of adherence to treatment for each anti-TNF alpha therapy and all indications are shown in Figure 1. Among the $94 \%$ of patients who did not switch, those treated with infliximab had the highest rate of adherence across all indications, which was $51 \%$, versus $27 \%$ with etanercept and $23 \%$ with adalimumab (Figure 1).

After adjusting for potential confounding variables, infliximab proved to be a protective predictor of nonadherence for all indications compared with patients in the adalimumab and etanercept groups (OR ranged from 0.08 to 0.43 ). A multivariable logistic model of nonadherence to treatment is shown in Table 2. Among patients who started a first-line biological drug (infliximab $n=303$, etanercept $n=437$, and adalimumab $n=115$, respectively), persistence in treatment was $73 \%$ for infliximab, $67 \%$ for etanercept, and $64 \%$ for adalimumab (Figure 2).

\section{Cost of illness}

The overall mean annual total health care cost for each patient in analysis was of $€ 11,120$, of which nonpharmacological costs were $€ 1,177$ and pharmacological costs $€ 9,943$. The mean hospital annual cost, calculated per patient according to the level of adherence, progressively and significantly increased in an inverse relationship with the level of adherence. The nonpharmacological expenditure for each patient in analysis was $€ 988$ for adherent and $€ 1,255$ for nonadherent patients. After adjusting for potential confounding factors, multivariate analysis results indicated a total health care cost for infliximab for all indications lower than for adalimumab and etanercept. Due to small sample size, models on ulcerative colitis, PsA, and AS did not converge (Table 3).

\section{Discussion}

The study was based on real-world utilization data among patients with medical conditions for which anti-TNF alpha agents are approved for use in Italy; ie, RA, psoriasis, PsA, AS, and inflammatory bowel disease. This approach provided a comprehensive evaluation of the relationship between treatment adherence and health care costs in patients treated with etanercept, adalimumab, or infliximab according to their therapeutic indications. Treatment adherence is a critical issue in the management of a considerable proportion of patients in anti-TNF therapy. Previous studies have suggested that the route and frequency of administration can affect patient treatment adherence, in addition to other reasons such as efficacy and toxicity. ${ }^{25-27}$ Unfortunately, the

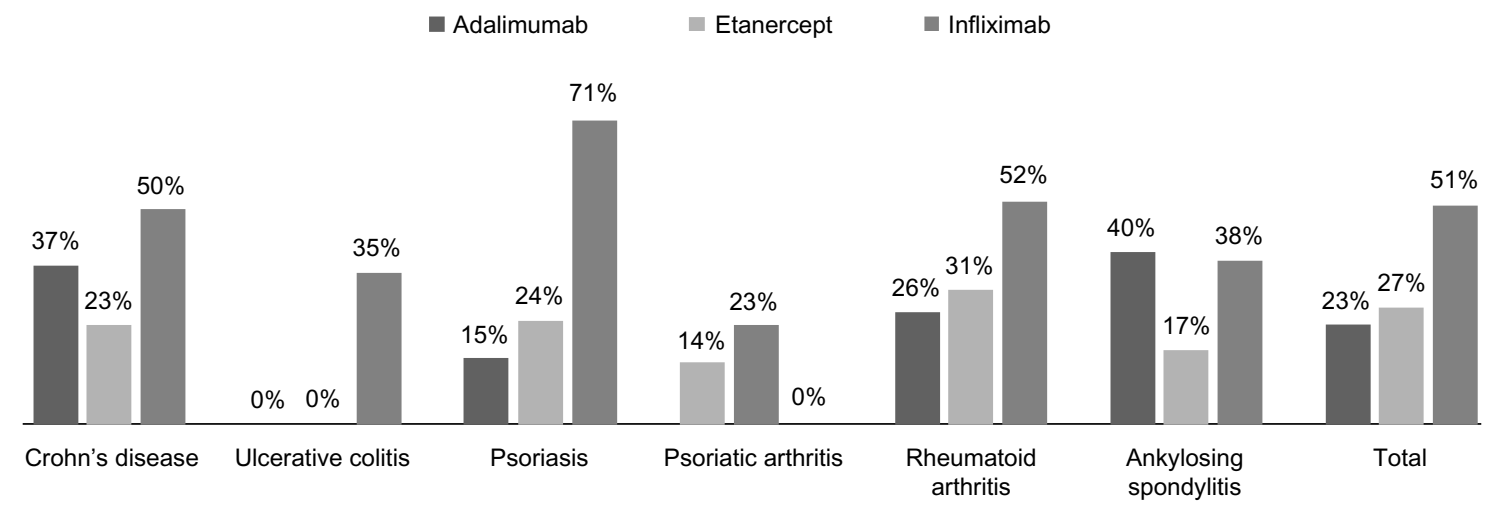

Figure I Adherence with treatment. 
Table 2 Multivariable logistic regression model of nonadherence to treatment

\begin{tabular}{|c|c|c|c|c|c|c|c|c|c|}
\hline & \multicolumn{3}{|c|}{ Crohn's disease } & \multicolumn{3}{|c|}{ Psoriasis } & \multicolumn{3}{|c|}{ Rheumatoid arthritis } \\
\hline & OR & $95 \% \mathrm{Cl}$ & $P$ value & OR & $95 \% \mathrm{Cl}$ & $P$ value & OR & $95 \% \mathrm{Cl}$ & $P$ value \\
\hline Male & 1.40 & $0.57-3.44$ & 0.465 & 1.08 & $0.61-1.91$ & 0.794 & 0.75 & $0.46-1.22$ & 0.247 \\
\hline Age & 0.99 & $0.96-1.02$ & 0.349 & 0.99 & $0.97-1.01$ & 0.577 & 1.00 & $0.98-1.02$ & 0.871 \\
\hline Stage & 1.24 & $0.42-3.60$ & 0.699 & $*$ & & & 2.31 & $0.99-5.40$ & 0.052 \\
\hline Etanercept ${ }^{* *}$ & 2.37 & $0.72-7.80$ & 0.155 & 0.51 & $0.27-0.97$ & 0.039 & 0.81 & $0.49-1.33$ & 0.403 \\
\hline Infliximab** & 0.43 & $0.15-1.27$ & 0.127 & 0.08 & $0.03-0.20$ & 0.000 & 0.28 & $0.13-0.58$ & 0.001 \\
\hline Established & 0.54 & $0.18-1.67$ & 0.285 & 0.53 & $0.29-0.95$ & 0.032 & 0.61 & $0.39-0.97$ & 0.038 \\
\hline MTX & 0.59 & $0.13-2.74$ & 0.501 & 1.06 & $0.46-2.46$ & 0.884 & 2.15 & $1.25-3.70$ & 0.006 \\
\hline DMARDs pre & 0.31 & $0.12-0.85$ & 0.022 & 0.62 & $0.34-1.12$ & 0.112 & 0.52 & $0.31-0.89$ & 0.018 \\
\hline$>I$ indication & 1.68 & $0.45-6.23$ & 0.437 & 1.48 & $0.63-3.50$ & 0.368 & 1.31 & $0.42-4.08$ & 0.637 \\
\hline
\end{tabular}

Notes: Due to small sample size, models on ulcerative colitis, psoriatic arthritis, and ankylosing spondylitis did not converge. *All patients with psoriasis were placed in stage I for disease severity; **versus adalimumab. Infliximab proved to be a protective predictor of nonadherence for all indications.

Abbreviations: DMARD, disease-modifying antirheumatic drug; MTX, methotrexate; OR, odds ratio; Cl, confidence interval; pre, previous use of DMARDs.

impact of nonadherence to anti-TNF alpha therapy can limit their potential benefit and may contribute to poor outcomes, including permanent joint and/or organ damage and increased utilization costs. ${ }^{28,29}$

Our study is the largest observational retrospective one to date and shows that patients treated with infliximab had a higher treatment adherence and persistence in treatment compared with patients treated with adalimumab and etanercept in all indications.

Multiple studies have examined persistence and adherence among real-world patients treated with anti-TNF alpha agents such as etanercept, infliximab, and adalimumab ${ }^{14,30-32}$ demonstrating that the overall treatment persistence with anti-TNF alpha therapies was different depending on the treatment.

A structured search of PubMed between 2001 and 2011 conducted to identify publications assessing the treatment with TNF-alpha inhibitors provided data about adherence in $\mathrm{CD}$ and RA. ${ }^{33}$ Three studies showed that in $\mathrm{CD}$ the adherence rate for infliximab (72\%) was higher compared to that of adalimumab (55\%), with a relative risk of 1.61 (95\% CI: $1.27-2.03)$, whereas in RA adherence to adalimumab (67\%) was higher compared to that of infliximab $(48 \%)$ and etanercept (59\%), with a relative risk of 1.41 (95\% CI, 1.3-1.52) and 1.13 (95\% CI, 1.10-1.18), respectively. In another comparative study, the RA adherence to infliximab was higher than with etanercept and adalimumab. ${ }^{33}$ In contrast, in a Swiss observational cohort of patients with RA $(\mathrm{N}=2,364)$ treated with at least one course of anti-TNF therapy from 1997 to 2006, the discontinuation rate was significantly higher among patients treated with infliximab compared with those treated with etanercept or adalimumab. ${ }^{34}$

A recent Italian retrospective analysis estimating the long-term survival rate of the first anti-TNF-alpha treatment in patients with psoriasis showed that patients treated with etanercept had a longer adherence (mean 51.4 months, $1,565$ days; $P<0,001)$ compared with those on infliximab (36.8 months, 1,120 days) or adalimumab (34.7 months, 1,056 days). ${ }^{35}$

Our data differ from those observed in the above studies, most likely because of the difference in the study design and the difference in data sources. Most European studies use registry-based databases, while US studies retrieve data

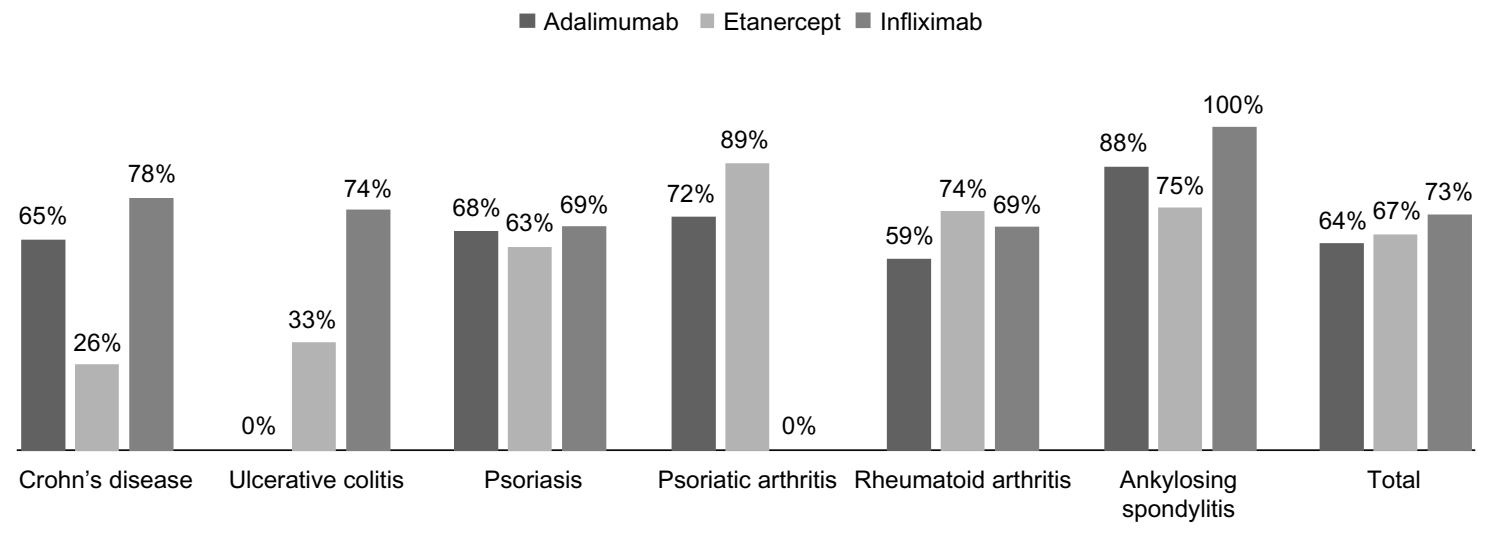

Figure 2 First biologic line: stay on treatment. 
Table 3 Cost of illness, generalized linear model

\begin{tabular}{|c|c|c|c|c|c|c|c|c|c|}
\hline & \multicolumn{3}{|c|}{ Crohn's disease } & \multicolumn{3}{|c|}{ Psoriasis } & \multicolumn{3}{|c|}{ Rheumatoid arthritis } \\
\hline & $\beta$ & $95 \% \mathrm{Cl}$ & $P$ value & $\beta$ & $95 \% \mathrm{Cl}$ & $P$ value & $\beta$ & $95 \% \mathrm{Cl}$ & $P$ value \\
\hline Male & 808 & $-\mid 76$ to $|, 79|$ & 0.108 & 423 & -452 to 1,299 & 0.343 & -84 & $-I, 011$ to 842 & 0.859 \\
\hline Age & -89 & -129 to -48 & 0.000 & II & -23 to 45 & 0.537 & 0 & -33 to 33 & 0.999 \\
\hline Stage & 1,056 & -284 to 2,396 & 0.122 & 740 & $-2,261$ to 3,740 & 0.629 & -705 & $-1,916$ to 507 & 0.255 \\
\hline Etanercept* & $-2,240$ & $-3,906$ to -573 & 0.008 & 721 & -168 to 1,610 & 0.112 & 589 & -355 to 1,534 & 0.221 \\
\hline Infliximab* & $-2,510$ & $-4,449$ to $-57 \mid$ & 0.011 & $-1,292$ & $-3,038$ to 453 & 0.147 & $-3,172$ & $-4,414$ to $-1,929$ & 0.000 \\
\hline Adherence $>80 \%$ & 10,416 & 7,137 to 13,694 & 0.000 & 8,931 & 7,335 to 10,527 & 0.000 & 7,264 & 5,918 to 8,611 & 0.000 \\
\hline Established & 1,296 & -986 to 3,577 & 0.266 & 1,012 & 4 to 2,019 & 0.049 & 2,465 & $\mathrm{I}, 44 \mathrm{I}$ to 3,490 & 0.000 \\
\hline$>I$ indication & 1,090 & $-1,457$ to 3,637 & 0.402 & 286 & -948 to $I, 520$ & 0.649 & I, I97 & $-1,024$ to 3,418 & 0.291 \\
\hline - Const & 8,710 & 5,574 to $1 \mathrm{I}, 846$ & 0.000 & 6,403 & 2,780 to 10,025 & 0.001 & 7,713 & 5,585 to 9,842 & 0.000 \\
\hline
\end{tabular}

Notes: Due to small sample size, models on ulcerative colitis, psoriatic arthritis, and ankylosing spondylitis did not converge. *Versus adalimumab. Infliximab was associated with the lowest cost for all indications.

Abbreviations: $\mathrm{Cl}$, confidence interval; const, model constant.

from administrative claims. ${ }^{15}$ We identified considerable variations in the definitions and methodologies of how adherence was measured in the studies, the major issue being the lack of agreement in terminology and methodologies for measurement of therapy course and outcome, making difficult a comparison of the results of studies assessing this issue. Three key aspects indicate that our results are more representative of a real-world scenario than those reported in the above studies; ie, the LHU involved covers the nationwide distribution, the methods to evaluate the adherence to the treatment were standardized, and all indications for each drug were evaluated.

In our study we found that the adherence to treatment was associated with decreased hospital health care costs. Based on our analysis, the annual TNF alpha-inhibitors cost per treated patient was the lowest for infliximab across all indications. The higher adherence level $(>80 \%)$ was associated with higher pharmacological costs ( $€ 14,890$ vs $€ 7,453)$, while patients with higher adherence rates had lower nonpharmacological costs (€988 vs $€ 1,255)$. In particular, patients with lower nonpharmacological costs utilized fewer medical resources, suggesting a positive effect on quality of life. Excluding confounding factors, infliximab proved to be a protective predictor of nonadherence for all indications. Information on patients' persistence with biological anti-TNF alpha therapies is limited and the effects of persistence on the cost of therapy are unknown. In agreement with our data, a retrospective study that measured the level of adherence to biologic regimens in patients with RA in clinical practice showed that patients treated with infliximab + MTX have significantly higher persistence compared with those treated with adalimumab + MTX or etanercept + MTX. Pharmacy costs were higher in patients with $>80 \%$ persistence, while nonpharmacy costs were lower. ${ }^{23}$
Information from our study appears relevant also beyond the Italian setting because it provides valuable information that integrates results from studies carried out in other countries. Future research should explore further determinants of nonadherence and continue to examine the efficacy of implementing various strategies to improve medication management in this patient population. Whether different routes of administration of anti-TNF alpha agents affect adherence to therapy and therapeutic outcomes should also be considered. The scientific literature suggests that the likelihood of adherence to IV treatment regimens is higher than with the SC routes. ${ }^{36} \mathrm{IV}$ dosing allows continuous dosage adjustments to be made, affording flexibility in matching patient needs at any given time during the infusion and helping to optimize overall treatment outcomes. Nonetheless, this question needs to be evaluated qualitatively and quantitatively by further research. A limitation of this study was that the reasons for nonadherence or discontinuation of treatment and the weight of the patients were not available from the administrative database.

\section{Disclosure}

The authors report no conflicts of interest in this work.

\section{References}

1. Zink A, Braun J, Listing J, Wollenhaupt J. Disability and handicap in rheumatoid arthritis and ankylosing spondylitis - results from the German rheumatological database. German Collaborative Arthritis Centers. J Rheumatol. 2000;27(3):613-622.

2. Borman P, Toy GG, Babaoğlu S, Bodur H, Ciliz D, Alli N. A comparative evaluation of quality of life and life satisfaction in patients with psoriatic and rheumatoid arthritis. Clin Rheumatol. 2007;26(3):330-334.

3. Büsch K, Ludvigsson JF, Ekström-Smedby K, Ekbom A, Askling J, Neovius M. Nationwide prevalence of inflammatory bowel disease in Sweden: a population-based register study. Aliment Pharmacol Ther. 2014;39(1):57-68.

4. Spector TD. Rheumatoid arthritis. Rheum Dis Clin North Am. 1990;16(3):513-537. 
5. Lebwohl M. Psoriasis. Lancet. 2003;361(9364):1197-1204.

6. Sieper J, Braun J. New treatment options in ankylosing spondylitis: a role for anti-TNFalpha therapy. Ann Rheum Dis. 2001;60 Suppl 3: iii58-iii61.

7. Jacobs P, Bissonnette R, Guenther LC. Socioeconomic burden of immune-mediated inflammatory diseases - focusing on work productivity and disability. $J$ Rheumatol Suppl. 2011;88:55-61.

8. Scott DL, Kingsley GH. Tumor necrosis factor inhibitors for rheumatoid arthritis. $N$ Engl J Med. 2006;355(7):704-712.

9. Humira (adalimumab) prescribing information. European Medicines Agency. Available at: http://www.ema.europa.eu/ema/index. jsp?curl=pages $/$ medicines $/$ human $/$ medicines $/ 000481 /$ human med_000822.jsp\&mid=WC0b01ac058001d124. Accessed June 28, 2014.

10. Enbrel (etanercept) prescribing information. European Medicines Agency. Available at: http://www.ema.europa.eu/ema/index. jsp?curl=pages/medicines/human/medicines $/ 000262 /$ human med_000764.jsp\&mid=WC0b01ac058001d124. Accessed June 28, 2014.

11. Remicade (infliximab) prescribing information. European Medicines Agency. Available at: http://www.ema.europa.eu/ema/index. jsp?curl=pages $/$ medicines $/$ human $/$ medicines $/ 000240 /$ human med_001023.jsp\&mid=WC0b01ac058001d124. Accessed June 28, 2014.

12. Hyrich KL, Lunt M, Watson KD, Symmons DP, Silman AJ; British Society for Rheumatology Biologics Register. Outcomes after switching from one anti-tumor necrosis factor alpha agent to a second anti-tumor necrosis factor alpha agent in patients with rheumatoid arthritis: results from a large UK national cohort study. Arthritis Rheum. 2007;56(1):13-20.

13. Peterson AM, Nau DP, Cramer JA, Benner J, Gwadry-Sridhar F, Nichol M. A checklist for medication compliance and persistence studies using retrospective databases. Value Health. 2007;10(1):3-12.

14. Blum MA, Koo D, Doshi JA. Measurement and rates of persistence with and adherence to biologics for rheumatoid arthritis: a systematic review. Clin Ther. 2011;33(7):901-913.

15. Markenson JA, Gibofsky A, Palmer WR, et al. Persistence with antitumor necrosis factor therapies in patients with rheumatoid arthritis: observations from the RADIUS registry. J Rheumatol. 2011;38(7): 1273-1281.

16. Cramer JA, Silverman S. Persistence with bisphosphonate treatment for osteoporosis: finding the root of the problem. Am J Med. 2006; 119(4 Suppl 1):S12-S17.

17. World Health Organization. Adherence to Long-Term Therapies: Evidence for Action. Geneva: World Health Organization; 2003.

18. Hughes D, Cowell W, Koncz T, Cramer J; International Society for Pharmacoeconomics and Outcomes Research Economics of Medication Compliance Working Group. Methods for integrating medication compliance and persistence in pharmacoeconomic evaluations. Value Health. 2007;10(6):498-509.

19. Cramer JA, Roy A, Burrell A, et al. Medication compliance and persistence: terminology and definitions. Value Health. 2008;11(1): 44-47.

20. Di Bari M, Balzi D, Roberts AT, et al. Prognostic stratification of older persons based on simple administrative data: development and validation of the "Silver Code," to be used in emergency department triage. J Gerontol A Biol Sci Med Sci. 2010;65(2):159-164.
21. Ministry of Labour, Health and Social Policies. Annual report on the hospitalization activity. 2005. Available from: http://www.ministerosalute.it/ programmazione/sdo/sezDocumenti.jsp?id=148\&label=osp. Accessed June 28, 2014

22. Gonnella JS, Louis DZ, Gozum MVE, Callahan CA, Barnes CA. Disease Staging Clinical and Coded Criteria. Version 5.26. Ann Arbor, MI: Thomson Reuters; 2009.

23. Tang B, Rahman M, Waters HC, Callegari P. Treatment persistence with adalimumab, etanercept, or infliximab in combination with methotrexate and the effects on health care costs in patients with rheumatoid arthritis. Clin Ther. 2008;30(7):1375-1384.

24. Catalan VS, LeLorier J. Predictors of long-term persistence on statins in a subsidized clinical population. Value Health. 2000;3(6): 417-426.

25. Claxton AJ, Cramer J, Pierce C. A systematic review of the associations between dose regimens and medication compliance. Clin Ther. 2001;23(8):1296-1310.

26. Barton JL. Patient preferences and satisfaction in the treatment of rheumatoid arthritis with biologic therapy. Patient Prefer Adherence. 2009;3:335-344.

27. Harley CR, Frytak JR, Tandon N. Treatment compliance and dosage administration among rheumatoid arthritis patients receiving infliximab, etanercept, or methotrexate. Am J Manag Care. 2003; 9(Suppl 6):S136-S143.

28. Punzi L, Matucci Cerinic M, Cantini F, et al. Treatment patterns of anti-TNF agents in Italy: an observational study. Reumatismo. 2011;63(1):18-28

29. Williams A, Manias E, Walker R. Interventions to improve medication adherence in people with multiple chronic conditions: a systematic review. J Adv Nurs. 2008;63(2):132-143.

30. Yazici Y, Krasnokutsky S, Barnes JP, Hines PL, Wang J, Rosenblatt L. Changing patterns of tumor necrosis factor inhibitor use in 9074 patients with rheumatoid arthritis. J Rheumatol. 2009;36(5):907-913.

31. Oei HB, Hooker RS, Cipher DJ, Reimold A. High rates of stopping or switching biological medications in veterans with rheumatoid arthritis. Clin Exp Rheumatol. 2009;27(6):926-934.

32. Blom M, Kievit W, Fransen J, et al. The reason for discontinuation of the first tumor necrosis factor (TNF) blocking agent does not influence the effect of a second TNF blocking agent in patients with rheumatoid arthritis. J Rheumatol. 2009;36(10):2171-2177.

33. Fidder HH, Singendonk MM, van der Have M, Oldenburg B, van Oijen MG. Low rates of adherence for tumor necrosis factor- $\alpha$ inhibitors in Crohn's disease and rheumatoid arthritis: results of a systematic review. World J Gastroenterol. 2013;19(27):4344-4350.

34. Du Pan SM, Dehler S, Ciurea A, Ziswiler HR, Gabay C, Finckh A; Swiss Clinical Quality Management Physicians. Comparison of drug retention rates and causes of drug discontinuation between antitumor necrosis factor agents in rheumatoid arthritis. Arthritis Rheum. 2009;61(5):560-568.

35. Esposito M, Gisondi P, Cassano N, et al. Survival rate of antitumour necrosis factor- $\alpha$ treatments for psoriasis in routine dermatological practice: a multicentre observational study. Br J Dermatol. 2013;169(3): 666-672.

36. Schwartzman S, Morgan GJ. Does route of administration affect the outcome of TNF antagonist therapy?Arthritis Res Ther. 2004; 6 Suppl 2:S19-S23.
ClinicoEconomics and Outcomes Research

\section{Publish your work in this journal}

ClinicoEconomics \& Outcomes Research is an international, peerreviewed open-access journal focusing on Health Technology Assessment, Pharmacoeconomics and Outcomes Research in the areas of diagnosis, medical devices, and clinical, surgical and pharmacological intervention. The economic impact of health policy and health systems

\section{Dovepress}

organization also constitute important areas of coverage. The manuscript management system is completely online and includes a very quick and fair peer-review system, which is all easy to use. Visit http://www.dovepress.com/testimonials.php to read real quotes from published authors. 